\title{
Registry Protocol Identifier
}

National Cancer Institute

\section{Source}

National Cancer Institute. Registry Protocol Identifier. NCI Thesaurus. Code C132348.

A unique code, which is assigned by the clinical trial registry, that identifies a specific

protocol. 